\title{
Moisture transport and Antarctic sea ice: austral spring 2016 event
}

\author{
Monica Ionita, Patrick Scholz, Klaus Grosfeld, and Renate Treffeisen \\ Alfred Wegener Institute Helmholtz Centre for Polar and Marine Research, 27570 Bremerhaven, Germany \\ Correspondence: Monica Ionita (monica.ionita@awi.de)
}

Received: 17 November 2017 - Discussion started: 18 December 2017

Revised: 11 May 2018 - Accepted: 15 June 2018 - Published: 4 July 2018

\begin{abstract}
In austral spring 2016 the Antarctic region experienced anomalous sea ice retreat in all sectors, with sea ice extent in October and November 2016 being the lowest in the Southern Hemisphere over the observational period (1979-present). The extreme sea ice retreat was accompanied by widespread warming along the coastal areas as well as in the interior of the Antarctic continent. This exceptional event occurred along with a strong negative phase of the Southern Annular Mode (SAM) and the moistest and warmest spring on record, over large areas covering the Indian Ocean, the Ross Sea and the Weddell Sea. In October 2016, the positive anomalies of the totally integrated water vapor (IWV) and $2 \mathrm{~m}$ air temperature (T2m) over the Indian Ocean, western Pacific, Bellingshausen Sea and southern part of Ross Sea were unprecedented in the last 39 years. In October and November 2016, when the largest magnitude of negative daily sea ice concentration anomalies was observed, repeated episodes of poleward advection of warm and moist air took place. These results suggest the importance of moist and warm air intrusions into the Antarctic region as one of the main contributors to this exceptional sea ice retreat event.
\end{abstract}

\section{Introduction}

Sea ice in both polar regions is an important indicator for the expression of global climate change and its polar amplification. It also plays an important role in modulating the global climate system by influencing the atmospheric and oceanic circulations (Cohen et al., 2018). Moreover, it also has a strong impact on the global economic system through changes in marine and natural resource development. Consequently, there is a broad scientific as well as societal interest in sea ice and its coverage, variability, and long-term change (National Research Council, 2012). Recent observed changes in the Arctic have become the "face" for global climatic changes, especially due to the rapidly decreasing trend in the summer sea ice extent (SIE) over the last 2 decades (Serreze and Stroeve, 2015). The trends in the Arctic SIE over the satellite observational record from 1979 to present are negative for all months, with the largest trend recorded at the end of the melt season in September (Serreze et al., 2007; Stroeve et al., 2015), with an average decline of $12.9 \%$ per decade relative to the long-term mean of the 1981-2010 September average (Grosfeld et al., 2016).

In contrast, over the Antarctic region the SIE shows an increasing trend over the satellite observational record, seemingly at odds with climate model projections. The increase in the Antarctic SIE can be largely explained by natural climate fluctuations (Meehl et al., 2016), linked with different factors/drivers like atmospheric temperature or wind stress (Liu et al., 2004; Turner et al., 2009; Lefebvre and Goosse, 2005), precipitation (Liu and Curry, 2010), ocean temperature (Jacobs and Comiso, 1997), and feedbacks in the atmosphere or ocean (Stammerjohn et al., 2012; Zhang, 2007). The variability in the Antarctic SIE has also been related to several large-scale atmospheric circulation mechanism like (a) the Southern Annular Mode (SAM) (Hall and Visbeck, 2002; Kwok and Comiso, 2002; Lefebvre et al., 2004; Simpkins et al., 2012; Raphael and Hobbs, 2014); (b) the zonal wave 3 (ZW3) (Raphael, 2007, Schlosser et al., 2018), and (c) the El Niño-Southern Oscillation (Turner, 2004; Yuan, 2004; Stammerjohn et al., 2008). 
Whereas the coupled atmosphere-ocean-sea ice models, which are driven by realistic natural and anthropogenic forcing, are able to replicate the decreasing Arctic trend (Stroeve et al., 2012), they also have the tendency to simulate a significant decrease in Antarctic sea ice cover (Turner et al., 2013), in contrast with the observed increasing trend. Shu et al. (2015) showed that only one out of seven CMIP5 models is able to simulate the sign of the Antarctic sea ice trend correctly. As the confidence on numerical simulations relies on an adequate representation of the late-twentieth-century changes (Collins et al., 2014), the understanding of the physical processes generating the Antarctic SIE trend and variability is crucial for the relevance of the projected Southern Hemisphere (SH) SIE decrease. Consequently, the analyses of observed, reconstructed, and reanalysis data are critical for the investigation of their causes. Following this, here we analyze the exceptional Antarctic austral spring (SeptemberOctober-November) of 2016 from a climatological point of view and try to identify the drivers responsible for triggering this particular event. This study is an additional contribution in the discussion about the possible drivers of the 2016 extremely low sea ice event over the Antarctic region. Turner et al. (2017) considered the spatial differences of the SIE anomalies and their temporal change at a regional level. They related the low SIE over the Antarctic region to the warm air advection and the strong negative values of the SAM in November and December 2016. Schlosser et al. (2018) have shown that the rapid decrease in the sea ice area and extent were associated with atmospheric flow patterns reminiscent of a positive ZW3 index. The strong meridional flow associated with a positive ZW3 index triggered an accelerated sea ice decline, especially at the beginning of November. From a preconditioning point of view, Stuecker et al. (2017) showed that the extreme low SIE in November and December 2016 was partially driven by the 2015/2016 El Niño event and the negative phase of the SAM.

Due to the fact that the Arctic and Antarctic regions are moisture flux convergence areas, atmospheric moisture transport is a primary input source of water into these regions. Moreover, through the cloud radiative forcing the moisture transport directly or indirectly affects the snow, sea ice, and ice sheet over the polar regions. For the Arctic region, Kapsch et al. (2013) demonstrated that a significantly enhanced transport of humid air during spring produces increased cloudiness and humidity, thus accelerating the sea ice retreat in summer. Therefore, atmospheric moisture transport is a crucial component for the water balance, especially over the polar regions. While for the Arctic regions there are a large number of studies dealing with the influence of the moisture transport on the sea ice variability (Mortin et al., 2016; Yang and Magnusdottir, 2017; Park et al., 2015), over the Antarctic region little attention has been paid to transport variations in moisture from the extratropics (Nieto et al., 2017). As such, the objectives of our paper are as follows: (a) to characterize the temporal and spatial extent of the spring 2016 exceptional sea ice melting event using both daily and monthly sea ice data; (b) to analyze the key drivers of the event, with a special emphasis on the role played by enhanced moisture transport and warm intrusions into the Antarctic region; (c) to place the austral spring 2016 into a long-term perspective. The paper is structured as follows: in Sect. 2, we introduce the data used in this study; the main results of our analysis are shown in Sect. 3 while the concluding remarks are presented in Sect. 4.

\section{Data and methods}

\subsection{Data}

For the daily sea ice concentration (SIC) we utilize the passive microwave SIC data using the National Snow and Ice Data Center (NSIDC) bootstrap algorithm (Comiso and Nishio, 2008; Meier et al., 2013) over the period 1979-2016. Prior to 1987, data are only available every other day; hence data for missing days were produced using linear interpolation for each pixel among the fields of the previous and next days. The linear interpolation is a standard procedure of this sea ice product. The monthly SIE index (Fetterer et al., 2016) over the Antarctic region has been extracted from the NSIDC FTP server (ftp://sidads.colorado.edu/DATASETS/ NOAA/G02135/north/, last access: 17 October 2017). SIE is defined as the total area of all satellite pixels in which the SIC equals or exceeds $15 \%$. Following previous studies (Zwally et al., 2002; Turner et al., 2017), we examine the anomalies of the daily and monthly SIC and SIE for the Southern Ocean as a whole and for five separate sectors (Fig. 1): the Ross Sea (RS) $\left(160^{\circ} \mathrm{E}-130^{\circ} \mathrm{W}\right)$, AmundsenBellingshausen Sea (ABS) $\left(130-60^{\circ} \mathrm{W}\right)$, Weddell Sea (WS) $\left(60^{\circ} \mathrm{W}-20^{\circ} \mathrm{E}\right)$, Indian Ocean (IO) $\left(20-90^{\circ} \mathrm{E}\right)$, and western Pacific Ocean (WPO) $\left(90-160^{\circ} \mathrm{E}\right)$.

For the SH temperature and atmospheric circulation, we use the monthly means of air temperature at 2 $\mathrm{m}(\mathrm{T} 2 \mathrm{~m})$, zonal wind at $10 \mathrm{~m}(U)$, meridional wind at $10 \mathrm{~m}(V)$, mean sea level pressure (SLP), the vertical integral of water vapor (IWV), the vertical integral of eastward water vapor flux $\left(Q_{u}\right)$, the vertical integral of northward water vapor flux $\left(Q_{u}\right)$, the vertical integral of eastward heat flux $\left(H_{u}\right)$, and the vertical integral of northward heat flux $\left(H_{v}\right)$ from the European Centre for Medium-range Weather Forecasts (ECMWF) Interim (ERA-Interim) reanalysis fields (Dee et al., 2011). IWV, $Q_{u}, Q_{v}, H_{u}$, and $H_{v}$ are produced by the ERA post-processing budget software. Details on how the basic fields are post-processed are given in the IFS documentation (https://www.ecmwf.int/sites/default/files/elibrary/2017/ 17738-part-vi-technical-and-computational-procedures.pdf, last access: 18 April 2018). ERA-Interim uses a fourdimensional variational assimilation scheme with a $12 \mathrm{~h}$ analysis window. The data assimilation system is based on a 2006 version of the ECMWF Integrated Forecast Model. 
(a)

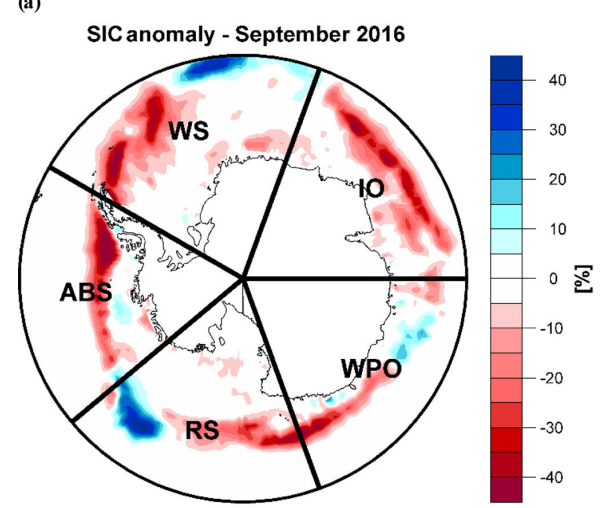

(c)

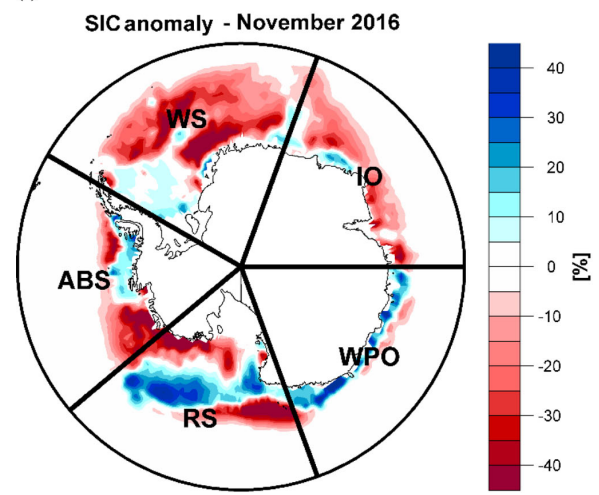

(b)

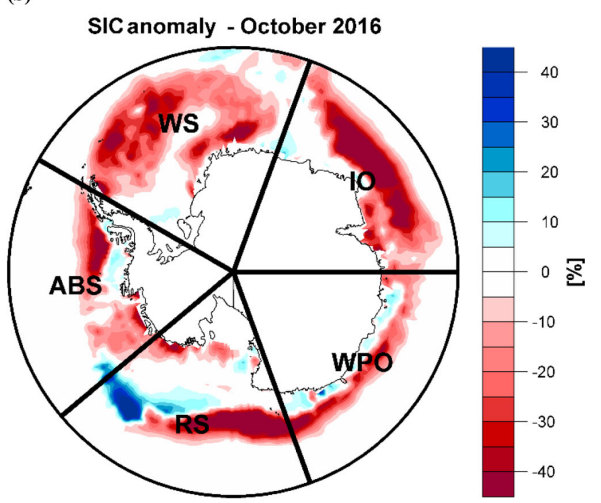

(d)

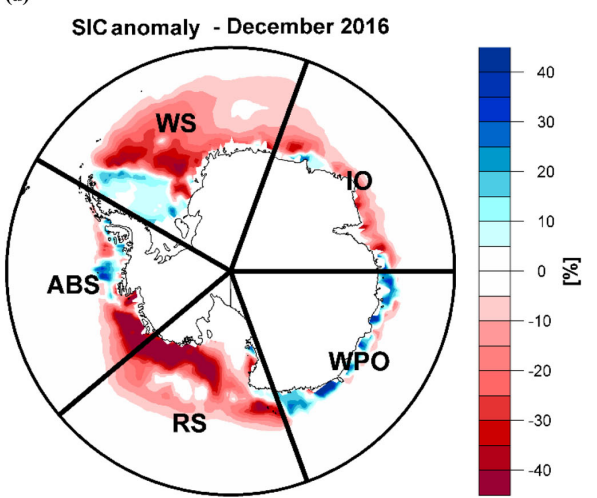

Figure 1. Sea ice concentration (SIC) anomalies 2016 for (a) September, (b) October, (c) November, and (d) December. The anomalies are computed relative to the reference period 1979-2010. WS: Weddell Sea; IO: Indian Ocean; WPO: western Pacific Ocean; RS: Ross Sea; ABS: Amundsen-Bellingshausen Sea.

The spatial resolution of the model is T255 $(\sim 80 \mathrm{~km})$ on 60 vertical levels from the surface up to $0.1 \mathrm{hPa}$ (Dee et al., 2011). The data are continuously updated in real time from 1 January 1979 to present. The ERA-Interim fields are reliable across high southern latitudes from 1979 and are considered to be the best reanalysis data set for depicting recent Antarctic climate (Bracegirdle and Marshall, 2012). They are typically considered to have the highest quality relative to other reanalysis data from the water cycle, with a better representation of mass fluxes including water vapor (Lorenz and Kunstamnn, 2012). The ERA-Interim data set has also been shown to significantly improve humidity fields in Antarctica and the Southern Ocean (Uppala et al., 2008; Simmons et al., 2010).

The vertically integrated water vapor transport (WVT) (Peixoto and Oort, 1992) is defined as follows:

$$
\boldsymbol{Q}(u, v, t)=Q_{u} \boldsymbol{i}+Q_{v} \boldsymbol{j},
$$

where $Q_{u}$ is the vertical integral of eastward water vapor flux and $Q_{v}$ the vertical integral of northward water vapor flux.

The station-based monthly mean temperature data have been extracted from the Reference Antarctic Data for Environmental Research (READER). The primary sources of data are the Antarctic research stations and automatic weather sta- tions. The stations used in the current study have been downloaded from the following website: https://legacy.bas.ac.uk/ met/READER/data.html (last access: 11 September 2017).

For the SAM index, we used the index from https:// legacy.bas.ac.uk/met/gjma/sam.html (last access: 11 September 2017). The SAM index is available from 1957 up to now and the index is computed from surface meteorological observations from Antarctic coastal and Southern Ocean island stations (Marshall, 2003). SAM is the dominant mode of lowfrequency atmospheric variability in the SH. The SAM index measures a "seesaw" of atmospheric mass between the middle and high latitudes of the SH. Positive values of the SAM index correspond with stronger-than-average westerlies over the middle to high latitudes $\left(50-70^{\circ} \mathrm{S}\right)$ and weaker westerlies in the midlatitudes $\left(30-50^{\circ} \mathrm{S}\right)$ (Marshall, 2003). All the anomalies (SIC, SLP, T2m, IWV, $Q_{u}, Q_{v}, H_{u}$, and $H_{v}$ ) used in this study were computed relative to the climatological period 1981-2010.

\subsection{Methods}

The stability maps approach used in this study is based on a methodology that was successfully applied to predict the monthly to seasonal streamflow of the Elbe and 
Rhine rivers (Ionita et al., 2008, 2014, 2017; Meißner et al., 2017). The basic idea of the stability maps is to identify regions with stable teleconnections (the correlation does not change in time) between SIE averaged over specific regions and meteorological-climatological gridded data. As such, we correlate the regional sea ice index with IWV and $\mathrm{T} 2 \mathrm{~m}$ gridded fields in a 21-year moving window. The correlation is considered to be stable for those grid points at which the sea ice index and the gridded fields are significantly correlated at the $95,90,85$, and $80 \%$ significance levels, for more than $80 \%$ of the 21 -year moving windows. The regions where the correlation is positive and stable will be represented as dark red ( $95 \%$ significance level), red (90\% significance level), orange ( $85 \%$ significance level), and yellow ( $80 \%$ significance level) on the stability maps (see Figs. 6 and 7). The regions where the correlation between the regional SIE index and the gridded data is stable and negative will be represented as dark blue (95\% significance level), blue (90\% significance level), green ( $85 \%$ significance level), and light green ( $80 \%$ significance level) on the stability maps (see Figs. 6 and 7). For the current analysis only regions where the correlation is above $95 \%$ significance level, are retained for further analysis. The results remain qualitatively the same if the length of the moving window varies between 15 and 25 years. Although the length of our time series is relatively short (40 years), the methodology proved to also work in cases of time series of $<$ 40 years (Ionita, 2017). Moreover, we use the same methodology, with the same number of years (40 years) for the prediction of September Arctic and Antarctic sea ice (https: //www.arcus.org/sipn/sea-ice-outlook/2017/post-season, last access: 12 November 2017). A more detailed description of the stability maps approach can be found in Ionita et al. (2008) and Ionita (2017).

\section{Results}

\subsection{Daily and monthly Antarctic sea ice extent}

Antarctic sea ice has shown increased SIE, area, and concentration from the late 1970s until 2015. Even though the trend itself is modest (Yuan et al., 2017), it is somewhat challenging to explain in the context of the overall global warming signal. When looking at the SIE anomalies over the last 38 years, the first 8 months of 2016 are not particularly anomalous (not shown). Both July (Fig. S1a in the Supplement) and August 2016 (Fig. S1b) were characterized by slightly positive pan-Antarctic SIE anomalies. However, starting from September 2016, the situation changed dramatically. The Antarctic SIE from September until December 2016 was characterized by significant negative anomalies, with November and December 2016 ranking as the lowest SIE for those respective months in the sea ice record (Fig. S1). November mean SIE was more than 5 standard deviations below the 1981-2010 average (Stammerjohn and
Scambos, 2017). September 2016 ranks seventh in terms of lowest SIE on record, while October 2016 ranks second in terms of lowest SIE.

To have a clear picture of the spatial pattern of the extreme events in the austral spring of 2016, we have computed the SIC anomalies in each grid point, from September until December 2016 (Fig. 1). In September 2016, most of the Antarctic region was characterized by negative SIC anomalies (Fig. 1a), with some exceptions over the eastern part of the WS and the eastern part of the RS, where positive SIC anomalies prevailed. The same spatial pattern was also present in October 2016 (Fig. 1b), but with much higher amplitudes (SIC anomalies $<40 \%$ ) over the IO, WS, and the western part of RS. In November 2016, the negative SIC anomalies become very high in amplitude over the western part of the WS and the western part of the ABS (Fig. 1c). Weak positive SIC anomalies were present over the western part of the WS, as well as over the northeastern part of the RS and southeastern part of the ABS. Over the WPO, the SIC anomalies reversed their sign (negative to positive) in November compared to October 2016. In December 2016, the whole RS, as well as the ABS (with some small exceptions over the eastern part) and IO, was characterized by negative SIC anomalies (Fig. 1d).

When looking at the daily evolution of the SIE anomalies throughout the austral spring 2016, some striking features are present. In September 2016, most of the negative SIE anomalies at the circumpolar Antarctic level were mainly driven by the daily SIE anomalies over the IO and ABS (Fig. S2). In October 2016, all regions, except the WS, were characterized by daily negative SIE anomalies, especially the IO. The situation became very dramatic in November 2016, when daily negative SIE anomalies were recorded over all the analyzed regions (Fig. S2), especially the IO and WS (in the second part of November). The combined effect of all regions, showing daily negative SIE anomalies throughout all of November 2016, was a SIE anomaly below -2.2 million $\mathrm{km}^{2}$ around 20 November. In December 2016, the extreme daily SIE anomalies continued the decreasing trend, with a SIE anomaly below -2.7 million $\mathrm{km}^{2}$ occurring in the middle of the month. Most of the contribution to the extreme SIE anomalies in December 2016 came from the WS. By analyzing the daily SIE anomalies throughout the year 2016, one of the most striking features is the abrupt drop in SIE of more than 1.7 million $\mathrm{km}^{2}$ from the beginning of November 2016 until the middle of December 2016, which was unprecedented since the beginning of the 1980s (not shown).

\subsection{Climatological analysis of the austral spring 2016}

In September 2016, the atmospheric circulation features a center of negative SLP anomalies over the Antarctic continent flanked by three centers of positive SLP anomalies: one over the RS, one over the IO, and one over the WS. This SLP pattern was associated with positive temperature anomalies 
(a)

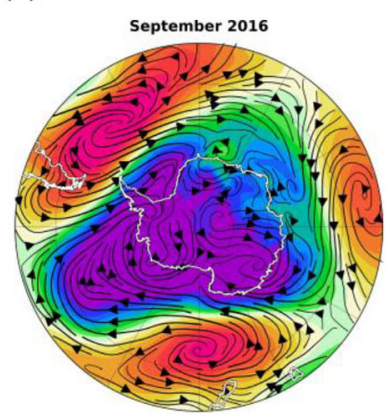

(e)

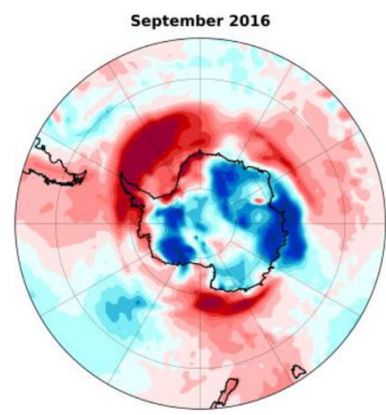

(b)

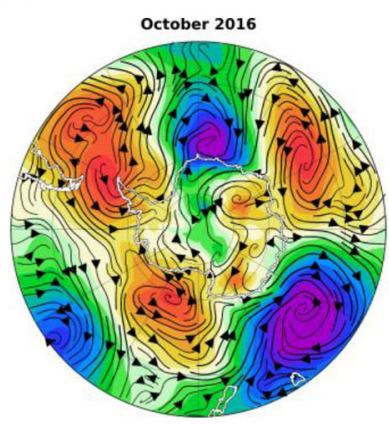

(f)

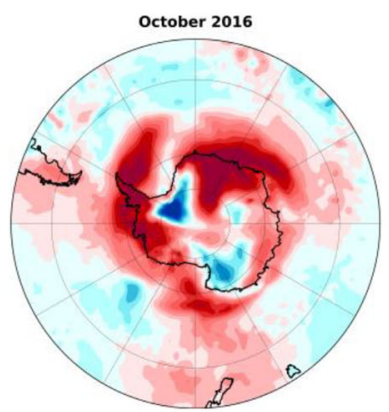

(c)

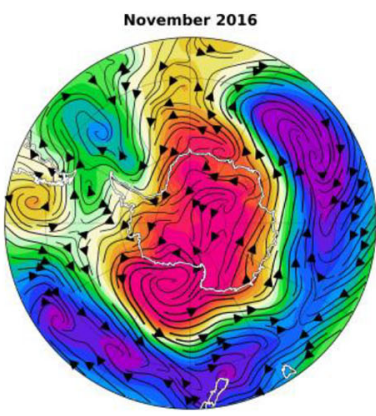

(g)

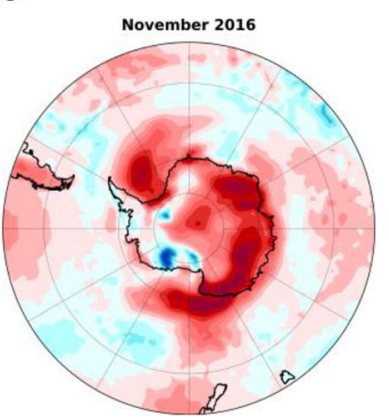

(d)
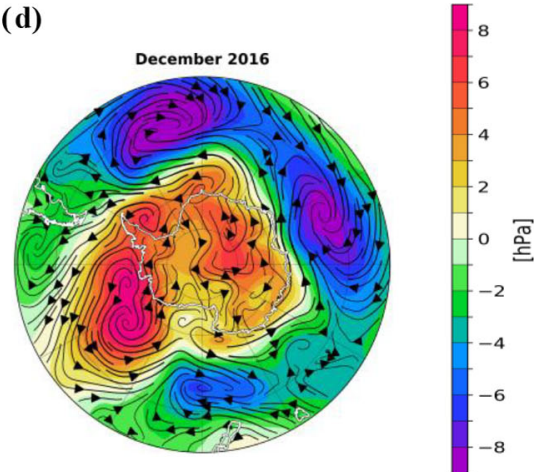

(h)

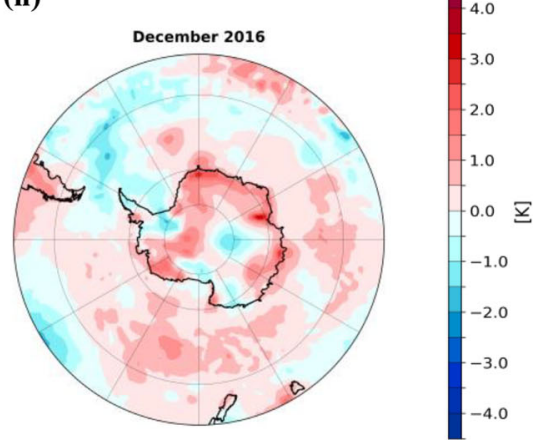

Figure 2. Sea level pressure (SLP) anomalies and the associated wind streamlines (a-d) and $2 \mathrm{~m}$ air temperature (T2m) anomalies (e-h) from September until December 2016. The anomalies are computed relative to the reference period 1979-2010.

over the ABS, WS, IO, and eastern WS and negative temperature anomalies over most of the Antarctic continent, except the Antarctic Peninsula (Fig. 2a). The three positive SLP centers were positioned in such a way that they enhanced the poleward advection of moist (Fig. 3a) and warm air (Fig. 4a), especially over the IO, eastern RS, WS, and Bellingshausen Sea (Fig. 2e). The areas, characterized by positive temperature anomalies and enhanced water vapor, correspond to the regions where the negative SIC anomalies occurred in September 2016 (see Fig. 1a).

In October 2016, the atmospheric circulation was more meridional and wavier, with altering positive and negative SLP anomalies surrounding the Antarctic continent (Fig. 2b). SAM had a value of -0.89 , ranking as the 14 th lowest SAM index on record. This wavy SLP pattern favored, again, the advection of moist (Fig. 3b) and warm air (Fig. 4b) towards the continent and the coastal areas, the most affected regions in terms of sea ice reduction, corresponding to the regions where warm and moist intrusions occurred: the WS, IO, ABS, and western WPO. October 2016 was also characterized by widespread warm anomalies along the coastal areas as well as in the interior of the continent, with some exceptions (Fig. 2f). In November 2016, the SAM index dropped to a value of -3.12 , which ranks as the fifth lowest SAM index since 1958 (Stammerjohn and Scambos, 2017). In terms of large-scale atmospheric circulation, an anomalous highpressure system developed over the polar cap, which resulted in the weakening of the westerlies. The high-pressure system over the southern polar cap was surrounded by a band of negative SLP anomalies, stretching from the IO-WPO-RS up to the ABS (Fig. 2c). Extreme positive temperature anomalies were recorded over the whole southern polar cap and the coastal areas (Fig. 2h). Moreover, over the ABS, WS, and RS, enhanced advection of moist (Fig. 3c) and warm (Fig. 4c) air from the lower latitudes led to a rapid melting of the sea ice over these regions (Fig. 1c).

In December 2016, the atmospheric circulation was similar to in November 2016: a high-pressure system over the southern polar cap, surrounded by negative SLP anomalies over the WS and IO (Fig. 2d). The December value of the SAM index $(-1.52,10$ th lowest for December since 1957) was much smaller compared to in November 2016. This is also visible in the amplitude of the SLP anomalies, over the polar cap, between the two months, with December 2016 featuring weaker (in amplitude) positive SLP anomalies over the Antarctic continent and smaller temperature anomalies (by a factor of 4 between November and December 2016). In December 2016, positive (but weak) temperature anomalies prevailed over most of the Antarctic continent, except for the central part (Fig. 2h). Moist (Fig. 3d) and warm (Fig. 4d) conditions were also recorded over the RS and parts of the coastal regions of the IO and WPO (Fig. 2h). 
(a)

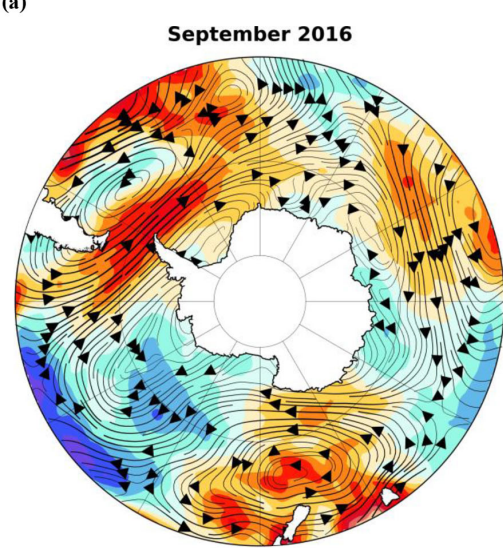

(c)

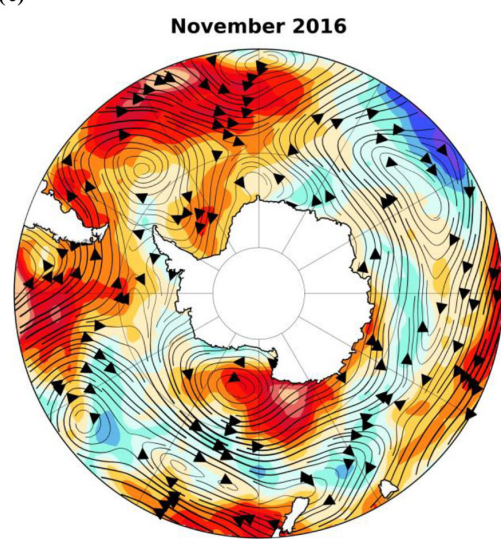

(b)

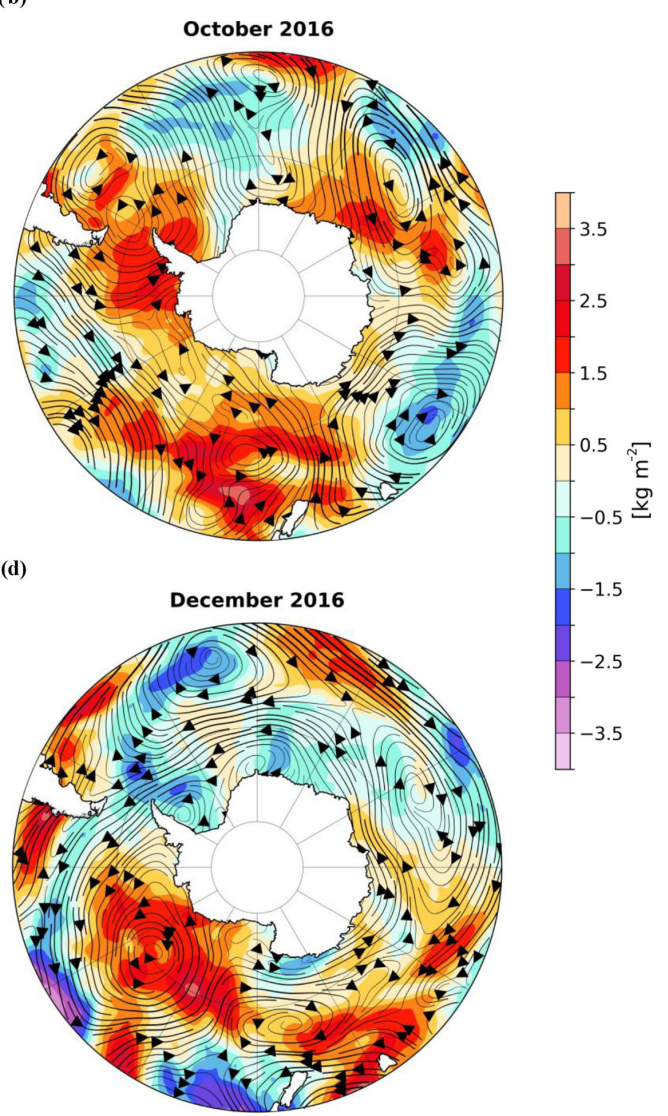

Figure 3. The vertical integral of water vapor anomalies (IWV, shaded areas) and the vertically integrated water vapor transport (WVT, streamlines) from September until December 2016. The anomalies are computed relative to the reference period 1979-2010.

\subsection{Long-term context of the austral spring 2016 event}

To demonstrate that austral spring 2016 was a very exceptional year in terms of reduced SIC and warm and moist conditions over the Antarctic region and the surrounding areas, we have computed the rank maps for the monthly (September-December) SIC (Fig. 5 - first column of panels), IWV (Fig. 5 - middle column of panels), and T2m (Fig. 5 - third column of panels) over the period 19792016. The red areas in Fig. 4 indicate that 2016 was the year with the lowest SIC, the moistest, and the warmest year on record over the period 1979-2016. The orange colors indicate that 2016 was the second lowest year in SIC, moisture, and warmth and so on. For clarity we have chosen only the top five ranks. The idea of ranking maps has been successfully used before to emphasize the exceptionality of a particular year/season/month (Ionita et al., 2017).

September 2016 was the month with the lowest SIC over distinct areas in the WS, RS, and ABS and ranks among the top five years with the lowest SIC over an extended band in the central IO (Fig. 5a). The regions with the lowest SIC, in September 2016, were also the moistest (Fig. 5b) and warmest (Fig. 5c) on record. The regions with the lowest
SIC in October 2016 (Fig. 5d) are similar to the ones from September 2016, but the spatial extent of low SIC anomalies is larger compared to in September 2016. October 2016 stands out as the moistest and warmest year on record over large areas covering the surroundings of Antarctica: almost the entire IO region stands out as the moistest and warmest on record, with small exceptions in the western part of it; the southern part of RS was also among the moistest and warmest regions on record, while the whole Bellingshausen Sea stands out in the first five moistest and warmest Octobers on record (Fig. 5e and f). The largest regions affected by low SIC were recorded in November 2016 (Fig. 5g), with the central IO, southeastern RS, and small parts of WS being the areas with the lowest SIC on record. In terms of moisture and warm temperatures, the regions that stand out as very extreme, in November 2016, are located over the western part of RS and the eastern part of Antarctica as well as over the WS (Fig. 5h and i). Around the coastal areas of East Antarctica all stations where measurements are available recorded the highest monthly mean temperatures in October and November 2016 (Casey: $-3.7^{\circ} \mathrm{C}$; Davis: $-2.2^{\circ} \mathrm{C}$; Syowa: $-4.7^{\circ} \mathrm{C}$; Fig. $6 \mathrm{a}$ and b) (Keller et al., 2017). In December 2016, the spatial extent of the extremely low SIC is 
(a)

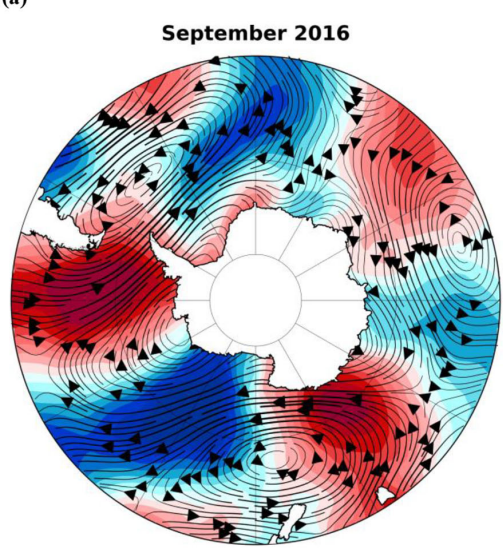

(c)

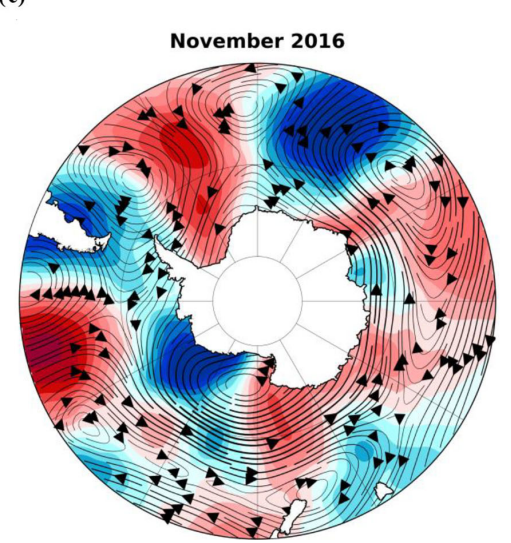

(b)

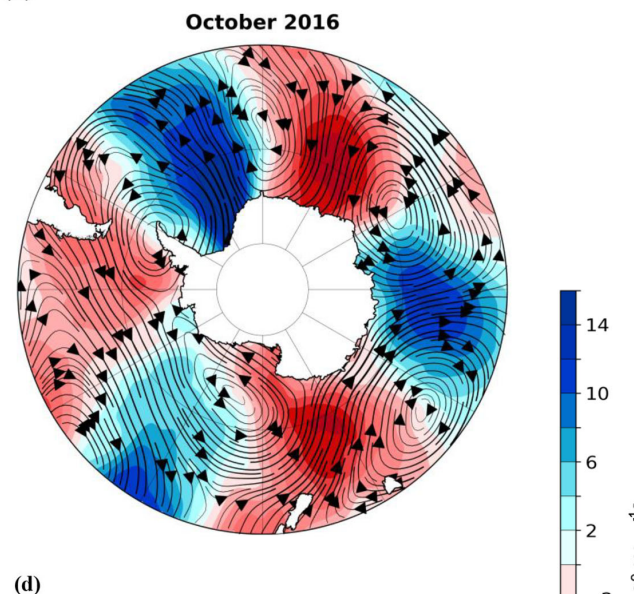

(d)

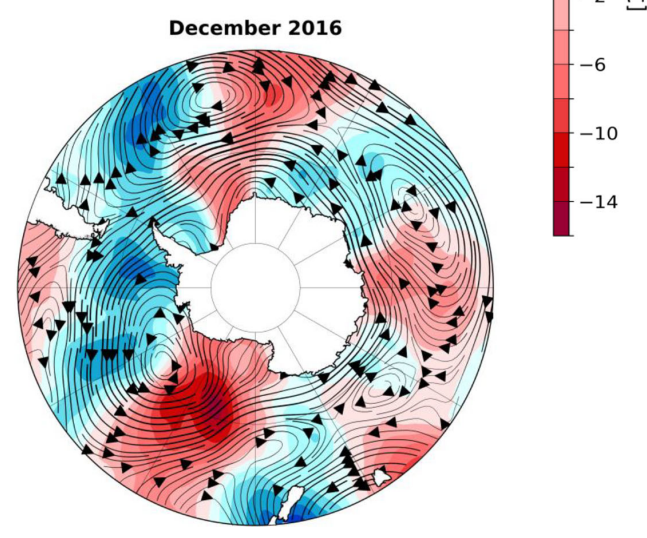

Figure 4. The vertical integral of northward heat flux (shaded areas) and the vertically integrated heat transport (streamlines) (c, d) from September until December 2016. The anomalies are computed relative to the reference period 1979-2010. In (a)-(d) positive anomalies indicate northward advection and negative anomalies indicate southward advection.

much smaller (Fig. 5j) compared to the previous months, being restricted just to the southern part of the RS and the eastern part of the ABS. The same is valid for IWV and T2m. The northeastern part of the RS ranks as the moistest on record (Fig. 5k), while small regions in the WS rank as the warmest on record (Fig. 5l).

\subsection{Long-term relationship between regional Antarctic sea ice, moisture availability and temperature}

As shown in Sect. 3.3, the period October-December 2016 was characterized by large positive anomalies in the surface temperature and the vertical integral of water vapor covering large areas in the Antarctic region (Figs. 2 and 3). To examine the long-term relationship between moisture and temperature on the one hand and the regional Antarctic sea ice variability on the other hand we have computed the stability maps between IO SIE (November) and IWV and T2m (October and November), as well as the stability maps between WS SIE (December) and November and December IWV and T2m (November and December), over the period 1979-2016.
We performed the analysis, both in phase as well as with 1month lag (IWV and T2m leading the regional SIE index) to have a clear picture of the relationship between SIE and IWV and T2m. We opted for November IO SIE and December WS SIE due to the fact that the highest SIE anomalies were recorded over these particular regions in 2016 (Fig. S2 and Table 1).

The stability maps between November IO SIE and October-November IWV and T2m are shown in Fig. 7a-d. In general, negative SIE anomalies over the IO, in November, tend to occur in association with enhanced moisture and positive temperature anomalies over the IO region in the previous month. In agreement with the findings in Sect. 3.3, the year 2016 stands out as the most extreme one both in terms of SIE and moisture availability. Based on the stable regions identified in Fig. 7a-d (marked by yellow boxes) we defined two indices: one for October IWV (IWV averaged over the region shown in the yellow box in Fig. 7a) and one for October $\mathrm{T} 2 \mathrm{~m}$ (T2m averaged over the region shown in the yellow box in Fig. 7c). For the in-phase stability maps (Fig. 7b and d), the stable regions are very small and very regional and 
SIC

(a)

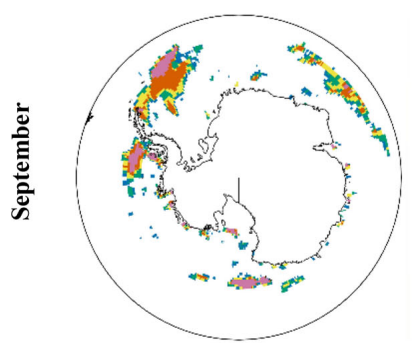

(d)

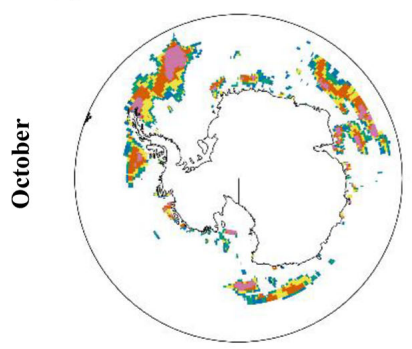

(g)

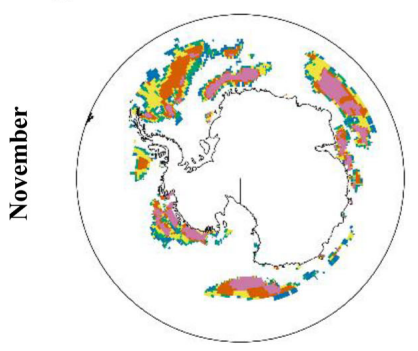

(j)

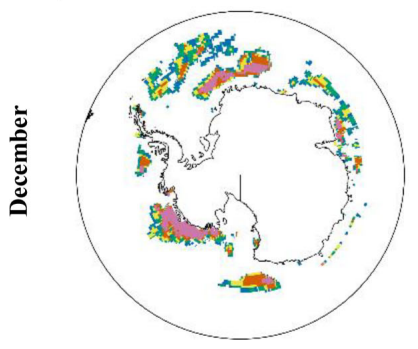

IWV

(b)

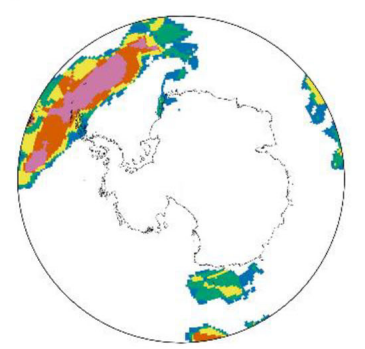

(e)

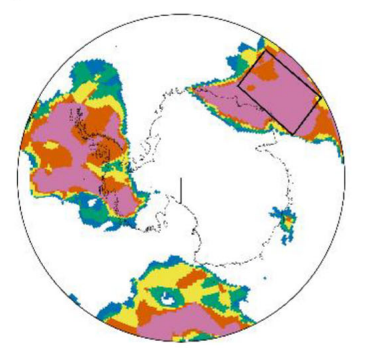

(h)

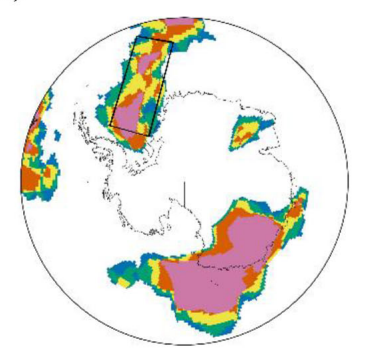

(k)

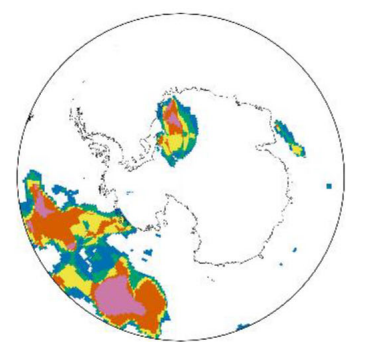

(c)

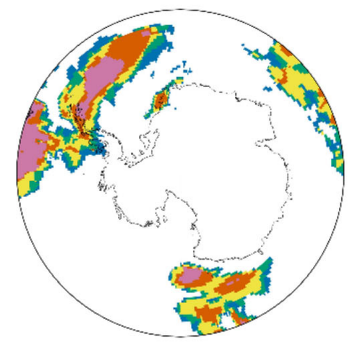

(f)

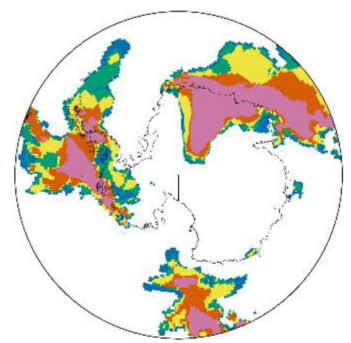

(i)

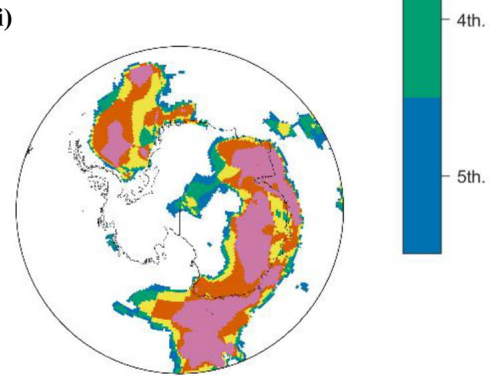

(l)

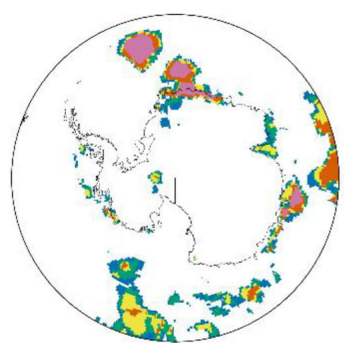

Figure 5. Ranking of 2016 monthly sea ice concentration (SIC - a, d, g, j; "1" means lowest SIC over the analyzed period), the vertical integral of water vapor (IWV - b, e, h, k; " 1 " means the moistest month over the analyzed period); $2 \mathrm{~m}$ air temperature (T2m - c, $\mathbf{f}, \mathbf{i}, \mathbf{l}$; " 1 " means the warmest month over the analyzed period). The analyzed period is 1979-2016. Rankings below five appear white.

we did not consider them for further analysis. The correlation coefficient between November IO SIE and the October IWV index is $r=-0.62$ (99\% significance level), while the correlation coefficient between the November IO SIE index and October T2m index is $r=-0.63$ (99\% significance level).

The stability maps between December WS SIE and November-December IWV and T2m are shown in Fig. 7a-d, respectively. In the case of December WS SIE, the stability maps show extended stable regions, with a dipole-like structure, both for November IWV and November T2m (marked by yellow and green boxes). Positive SIE anomalies over the WS, in December, are associated with negative IWV and $\mathrm{T} 2 \mathrm{~m}$ anomalies over the WS region and positive IWV and $\mathrm{T} 2 \mathrm{~m}$ anomalies over the RS, in the previous November. Based on the stability maps in Fig. 8a-d, we have defined five indices (yellow and green boxes in Fig. 8a, c, and d). As in the case of November IO, the stable regions are more extended for 1-month lag analysis. The correlation coefficient between December WS SIE and the November IWV1 index is $r=-0.68$ (99\% significance level) and the correlation be- 
(a)

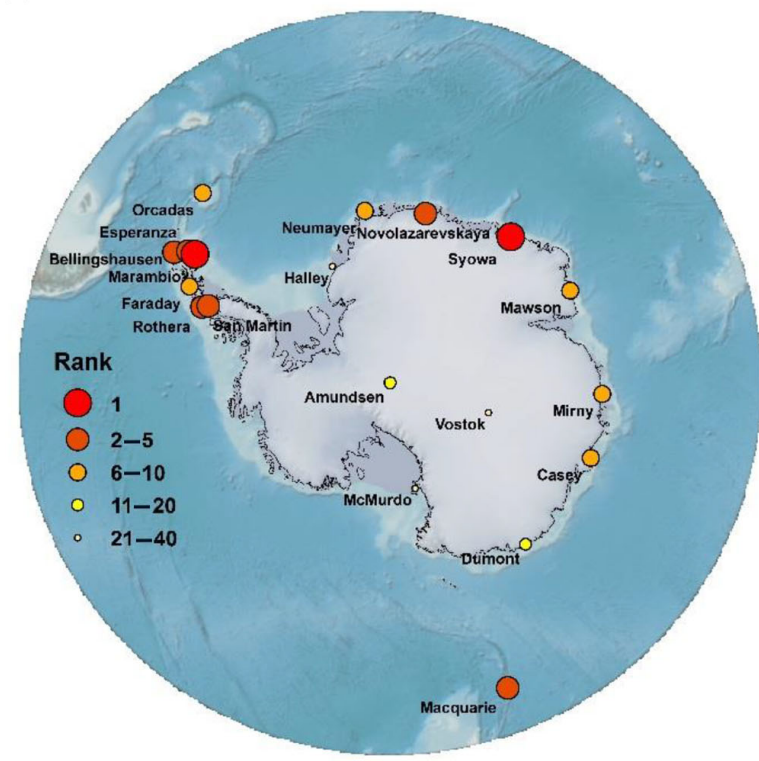

(b)

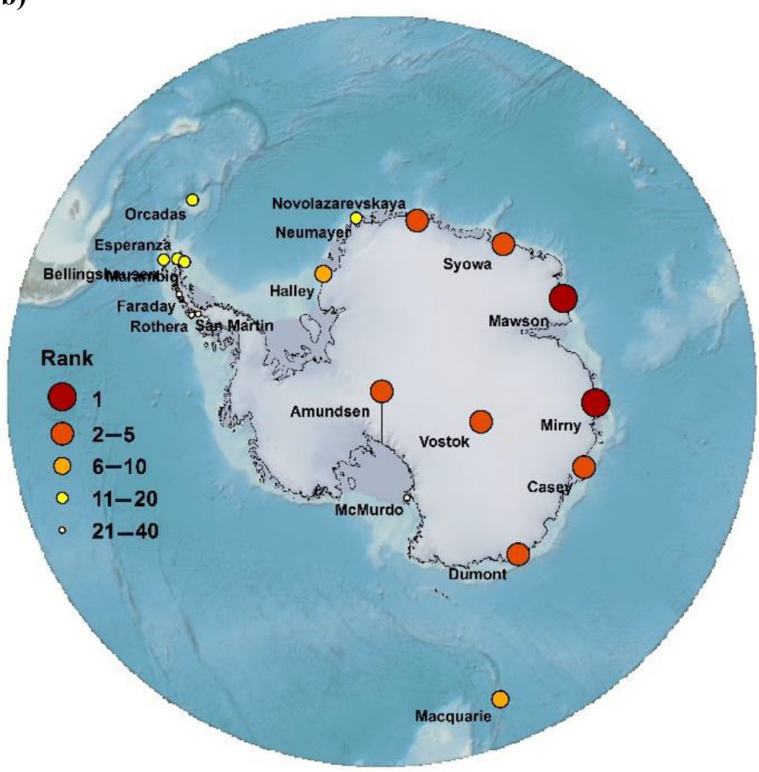

Figure 6. Ranking of the monthly mean temperature at observation stations: (a) October 2016 and (b) November 2016. The number "1" means the warmest month since 1981, number "2" signifies the second warmest, etc. The analyzed period is 1981-2016.

Table 1. Rank of regional sea ice extent from September to December 2016.

\begin{tabular}{lrrrr}
\hline & September & October & November & December \\
\hline ABS & 5 & 4 & 8 & 4 \\
IO & 2 & 2 & 1 & 2 \\
RS & 10 & 2 & 1 & 2 \\
WP & 15 & 11 & 1 & 22 \\
WS & 32 & 27 & 12 & 1 \\
ANT & 3 & 2 & 1 & 1 \\
\hline
\end{tabular}

tween the December WS SIE index and November T2m1 index is $r=-0.60$ (99\% significance level). The correlation coefficient between the December WS SIE and November IWV2 (T2m2) index is $r=0.34(0.45)$, while the correlation coefficient between December WS SIE and December T2m index is $r=-0.35$. Negative SIE anomalies, over the WS in December, occur in association with enhanced moisture and positive temperature anomalies over the WS and reduced moisture and negative temperature anomalies over the RS, in the previous month.

The significant lagged relationship between the regional SIE and previous month's IWV and T2m can be used as potential predictive information for the development of the upcoming SIE over particular regions. The same analysis can be performed for other regions or at the pan-Antarctic level and by including other climate and oceanic variables. Since the focus of our paper was to see the influence of the moisture and temperature on the development of the Antarctic sea ice extreme event in the austral spring of 2016, here we focused just on IWV and T2m.

\subsection{Daily evolution of the integrated water vapor transport in 2016}

So far we have considered only monthly means, but a signal that is visible at a monthly timescale has to have been predominant over a part of the month or extreme over particular days throughout the month (Schlosser et al., 2018). The later was the case for the moisture intrusions towards the Antarctic region, in October and November 2016. To emphasize the importance of these extreme daily moisture intrusions, based on the rank maps shown in Fig. 4, we have defined two indices over the regions which rank as the moistest on record in October and November (black squares in Fig. 5e and f). These indices have been computed by spatially averaging the daily vertical IWV over the months of October and November from 1979 until 2016. The two regions are defined over the IO (Fig. 9a) and WS (Fig. 10a).

Over the IO, two extreme events occurred in October 2016: one on 3 October (Fig. 9b) and the second one on 26 October (Fig. 9c). For these two extreme events the vertical IWV shows a band of enhanced moisture stretching from the IO towards the coastal eastern part of Antarctica (Fig. 9b and c). The regions with the highest IWV are located over the IO (black squares in Fig. 9b and c). Both events show clearly narrow bands, where the moisture fluxes are concentrated. These kind of events, also known as atmospheric rivers (ARs), have been associated with the occurrence of anomalous snow accumulation in East Antarctica 
(a)

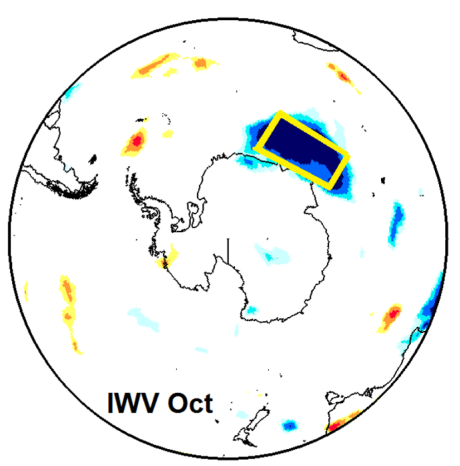

(c)

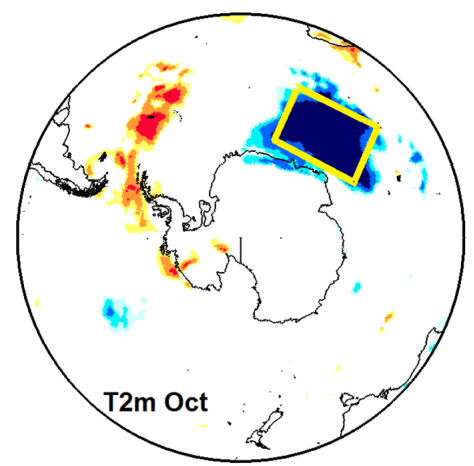

(e)

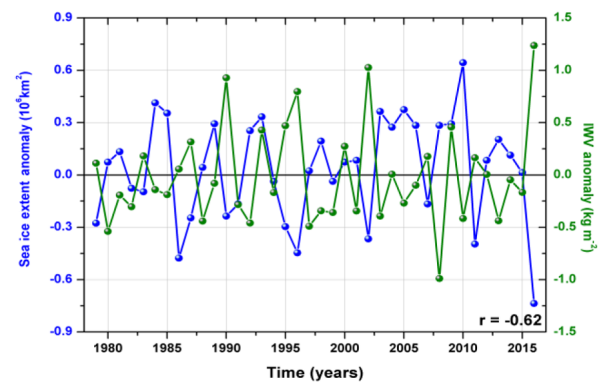

(b)

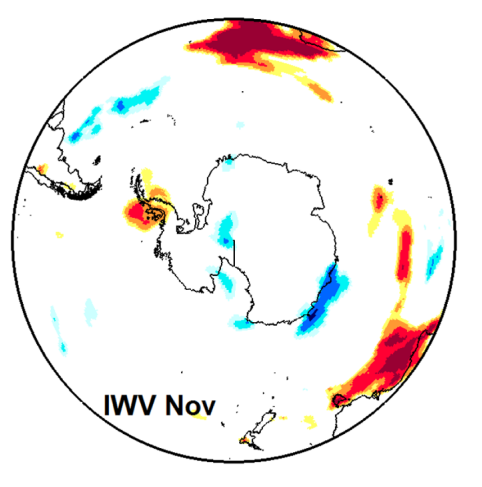

(d)

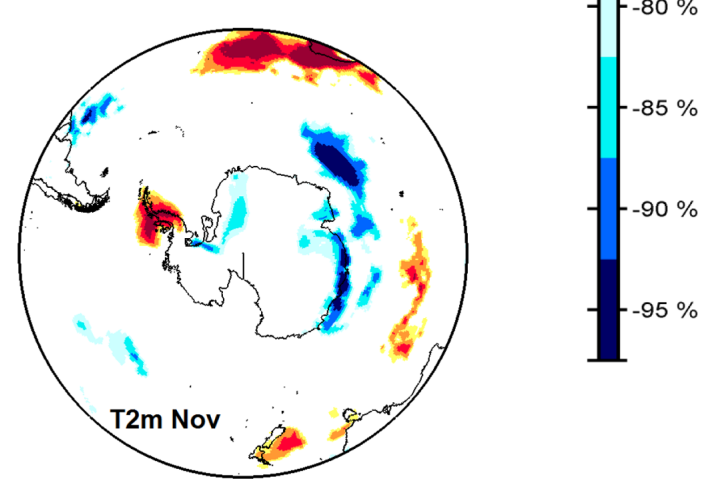

(f)

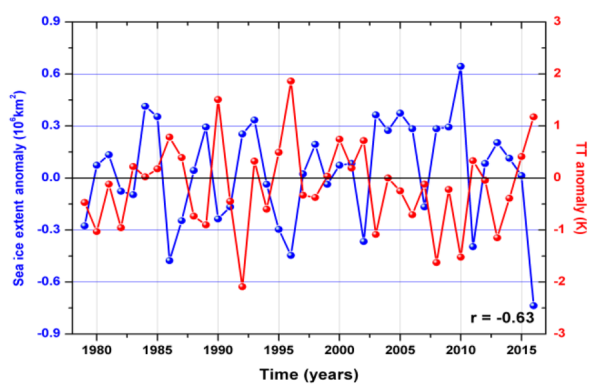

Figure 7. The stability maps between November Indian Ocean (IO) sea ice extent and (a) October IWV, (b) November IWV, (c) October $\mathrm{T} 2 \mathrm{~m}$, and (d) November T2m. (e) The time series of November IO SIE (blue line) and the time series of October IWV (green line) averaged over the yellow box in (a); (f) the time series of November IO SIE (blue line) and the time series of October T2m (red line) averaged over the region shown in the yellow box in (c). The regions where the correlation is positive and stable are represented as dark red (95\% significance level), red (90\% significance level), orange ( $85 \%$ significance level), and yellow ( $80 \%$ significance level) and the regions where the correlation between the regional SIE index and the gridded data is stable and negative are represented as dark blue (95\% significance level), blue (90\% significance level), green ( $85 \%$ significance level), and light green ( $80 \%$ significance level) on the stability maps.

(Gorodetskaya et al., 2014). In general, ARs transport large amounts of warm and humid air.

In November 2016, two extreme events also occurred (in terms of moisture transport): one on 3 November (Fig. 10a and $\mathrm{b}$ ) and the second one on 16 November (Fig. 10a and c). Although the IWV index is defined over a restricted area in the WS, when looking at the vertically integrated total moisture transport (vectors in Fig. 9b and c) and the associated IWV values, a very particular picture emerges. During these two particular events, the WS, IO, WPO, and ABS were un- der the influence of the advection of moist and warm air from the midlatitudes. The WS received enhanced moisture from the tropical South Atlantic Ocean, the IO received a band of enhanced moisture from both the tropical South Atlantic Ocean as well as from the IO, and the WPO received a lot of moisture from the IO. The combined effect of this enhanced moisture advection from the tropics, which happened simultaneously in the WS, IO, WPO, and ABS could, at least partly, explain the extremely low values of the daily SIE throughout the whole month of November 2016 and the 
(a)

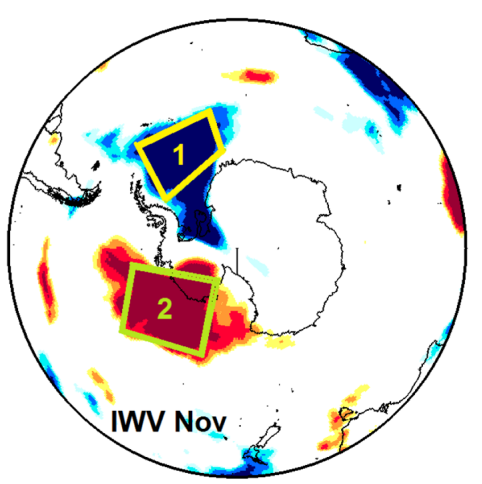

(c)

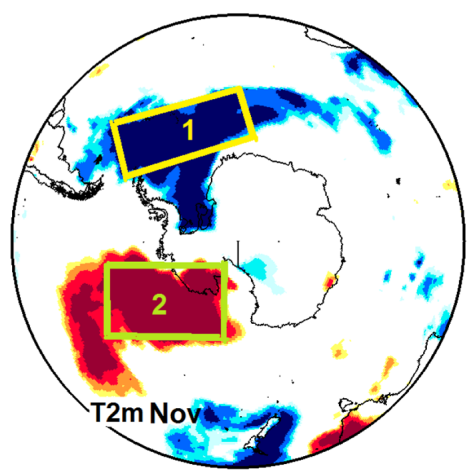

(e)

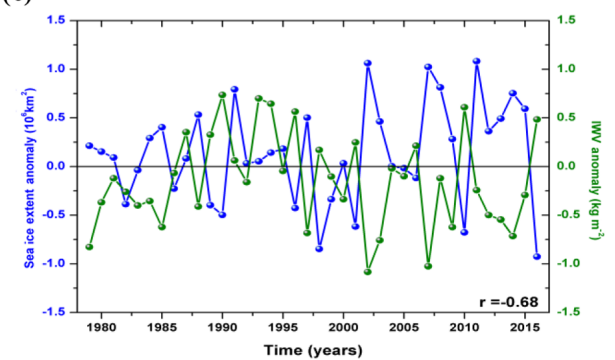

(b)

(d)

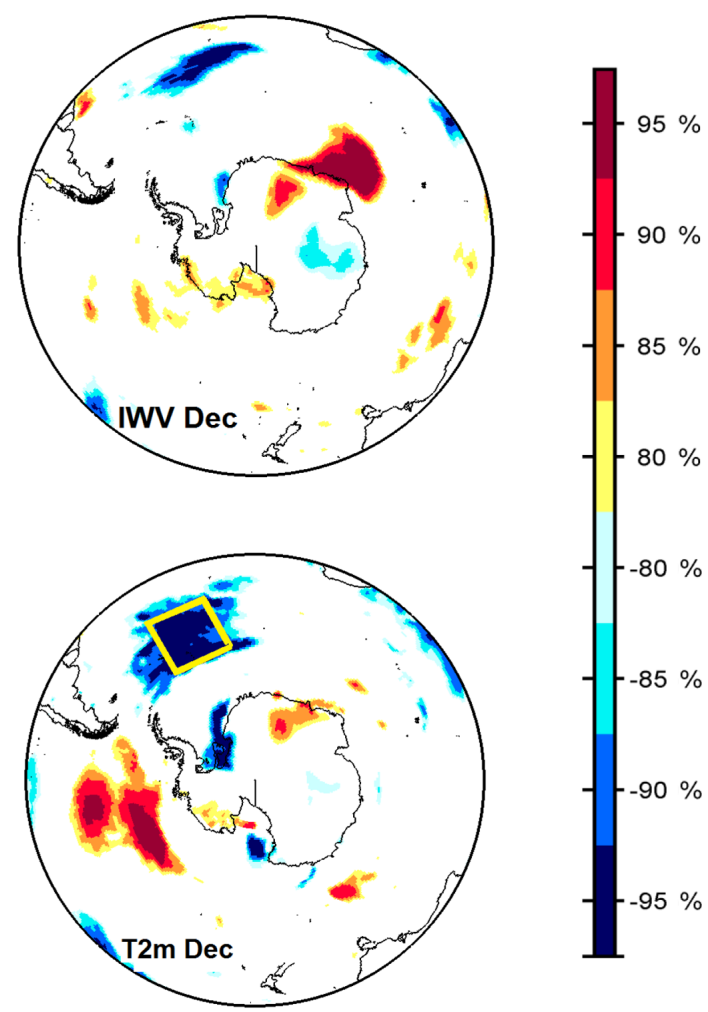

(f)

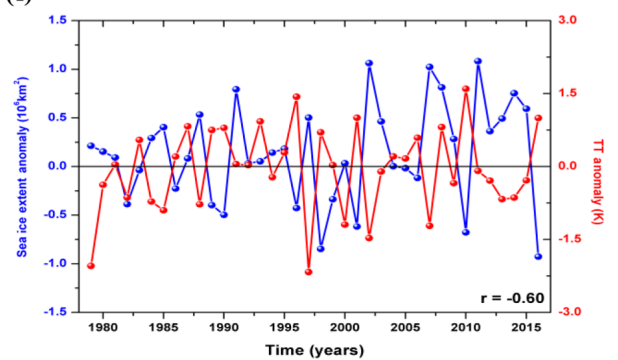

Figure 8. The stability maps between December Weddell Sea (WS) sea ice extent and (a) November IWV, (b) December IWV, (c) November $\mathrm{T} 2 \mathrm{~m}$, and (d) December T2m. (e) The time series of December WS SIE (blue line) and the time series of November IWV1 (green line) averaged over the region shown in the yellow box in (a); (f) the time series of December WS SIE (blue line) and the time series of November T2m1 (red line) averaged over the region shown in the yellow box in (b). The regions where the correlation is positive and stable are represented as dark red (95\% significance level), red (90\% significance level), orange (85\% significance level), and yellow ( $80 \%$ significance level) and the regions where the correlation between the regional SIE index and the gridded data is stable and negative will be represented as dark blue (95\% significance level), blue (90\% significance level), green (85\% significance level), and light green ( $80 \%$ significance level) on the stability maps.

beginning of December (Fig. S2). Looking at the daily vertically integrated total moisture transport, we can observe that moisture sources are coming from the tropical parts of the Pacific Ocean (for the ABS and RS), Atlantic Ocean (for the WS and IO), and Indian Ocean (for the IO and WPO). This is in agreement with a recent study of Drumond et al. (2016), who show that the most important moisture sources for the Antarctic ice cores are the subtropical South Atlantic Ocean, Indian Ocean, and South Pacific Ocean.

\section{Discussion and conclusions}

An initial attribution of the Antarctic conditions throughout the 2016 austral spring indicates that the atmospheric circulation in the SH was very anomalous. The SAM was negative from October until December 2016, with a top negative value of -3.12 in November 2016 (the fifth lowest SAM since 1958). The persistence of the negative phase of SAM throughout these 3 months is associated with a weakening of 
(a)

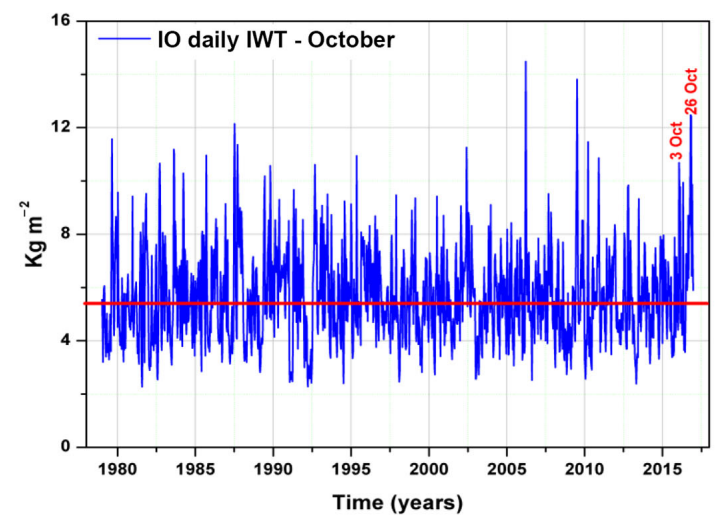

(b)

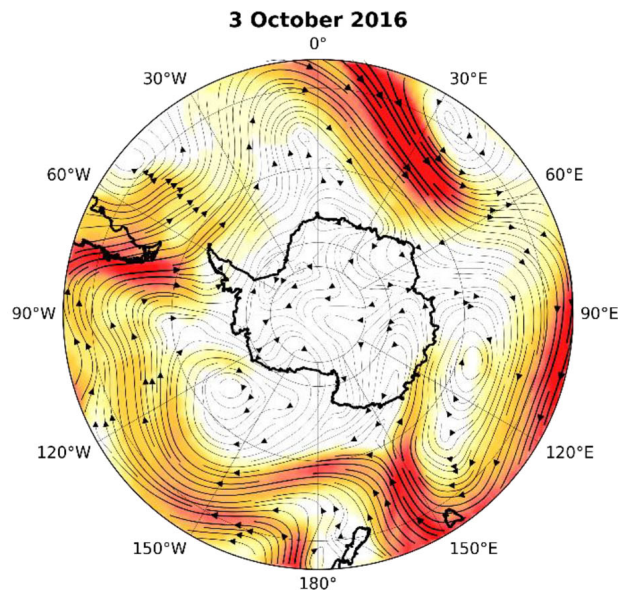

(c)

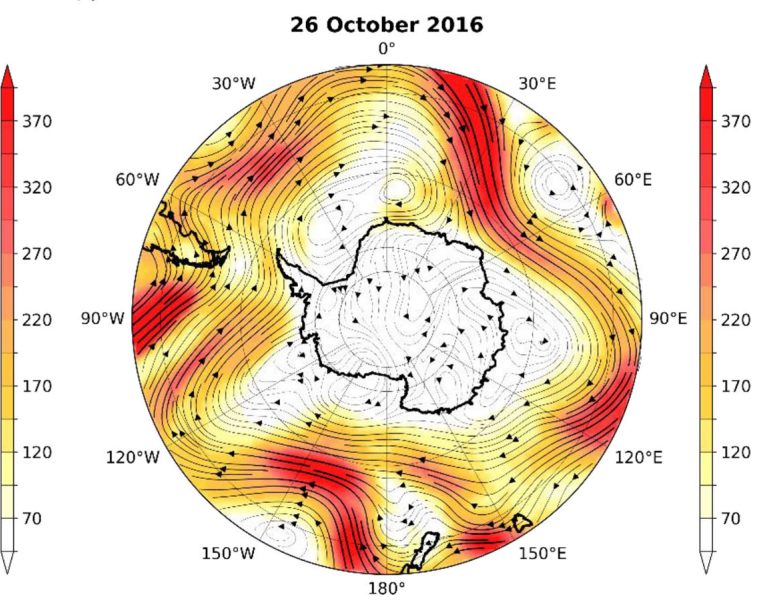

Figure 9. (a) Daily IWT averaged over the IO (black square in Fig. 4e) over the period 1979-2016; (b) the vertically integrated water vapor transport (WVT) on 3 October 2016 and (c) as in (b) but for 26 October 2016. In (b) and (c) the color-shaded areas indicated the magnitude of the moisture transport and the vectors the direction of the moisture transport.

the circumpolar westerlies and an overall surface warming of the coastal parts of the Antarctic continent, as well as large parts inside the continent. The overall warming accompanied by enhanced poleward advection of warm and moist air led to strong sea ice melting, especially in October and November. Tietäväinen and Vihma (2008) have shown that poleward water vapor transport, especially over the RS, WS, and IO, is usually associated with the SAM wave number 3 . This is in good agreement with our findings, especially for the months of October and November 2016.

The results presented in our study can be regarded as an additional contribution regarding the drivers of the 2016 extremely low sea ice event over the Antarctic region. In previous studies regarding the 2016 event, Turner et al. (2017) related this low SIE to the warm air advection and the strong negative values of SAM in November and December. Schlosser et al. (2018) have shown that the rapid decrease in the sea ice area and extent were associated with atmospheric flow patterns reminiscent of a positive zonal wave number 3 (ZW3) index, which triggered accelerated sea ice decline, especially at the beginning of November. Stuecker et al. (2017) showed that the extremely low SIE in November-December 2016 was partially driven by the 2015/2016 El Niño event and the negative phase of SAM. In our study, we show that enhanced moisture and positive temperature anomalies over different parts of the Antarctic region (e.g., IO, WS, RS) have led to the extremely low SIE recorded throughout the austral spring of 2016. In October and November 2016, when the lowest daily SIC anomalies were observed, repeated episodes of poleward advection of warm and moist air took place, with the most intense episodes occurring in October and November 2016. Moreover, October 2016 ranks as the moistest and warmest October over the last 39 years, over large areas in the IO, ABS, and RS (Fig. 5e and f), while November ranks as the moistest and warmest November over extended parts of the WS, WP, and WS (Fig. 5h and i). In this study, we have shown that negative SIE anomalies at the regional level (e.g., IO and WS) are preceded by enhanced moisture and positive temperature anomalies over these regions, 1 month ahead. The 
(a)

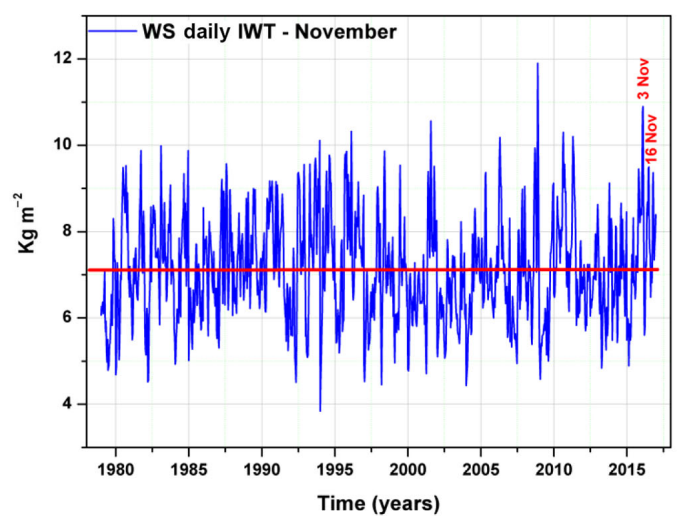

(b)

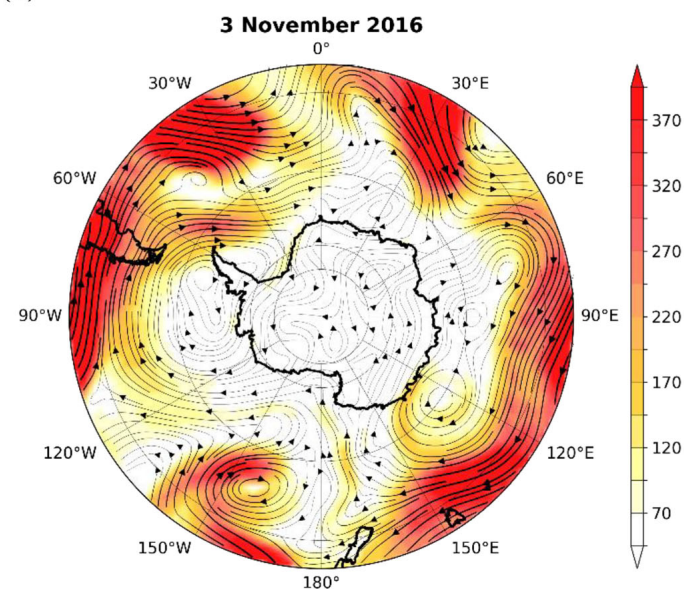

(c)

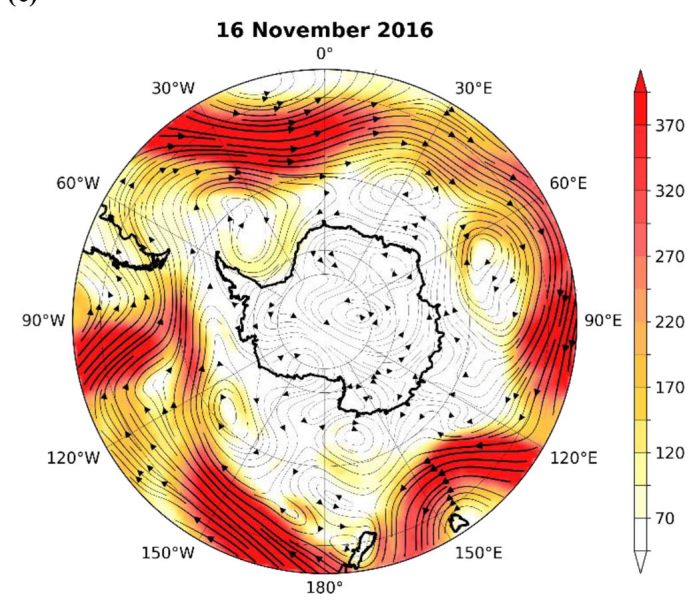

Figure 10. (a) Daily IWT averaged over the WS (black square in Fig. 4h) over the period 1979-2016; (b) the vertically integrated water vapor transport (WVT) on 3 November 2016 and (c) as in (b) but for 16 November 2016. In (b) and (c) the color-shaded areas indicated the magnitude of the moisture transport and the vectors the direction of the moisture transport.

lagged relationship between the regional SIE anomalies and the previous month's IWV and T2m could be used to provide a potential predictive skill for the upcoming development of the regional SIE anomalies.

Given the dramatic SAM anomalies in some months, we also investigated the long-term relationships between regional SIE and the monthly SAM (Table 2). However, significant relationships were found only for three month-region combinations and were thus consistent with previous studies (Stammerjohn et al., 2008; Lefebre et al., 2004; Holland et al., 2017; Liu et al., 2004; Simpkins et al., 2012). In September, significant correlations between SAM and regional SIE are found just for the WS $(r=-0.37,95 \%$ significance level), while for the other regions, the correlations are not significant. Throughout the month of October, no significant correlations are found between monthly SAM index and the regional Antarctic SIE, while for November significant correlations are found just between the SAM index and the IO ( $r=0.43,99 \%$ significance level). In December, significant correlations are found between the SAM index and the RS ( $r=0.46,99 \%$ significance level). Overall, positive
Table 2. Correlation coefficients between regional sea ice extent (SIE) and monthly Southern Annular Mode (SAM).

\begin{tabular}{lrrrr}
\hline & September & October & November & December \\
\hline ABS & 0.21 & 0.23 & 0.09 & 0.10 \\
IO & 0.07 & 0.17 & $0.43^{* *}$ & 0.31 \\
RS & -0.25 & -0.03 & 0.05 & $0.46^{* *}$ \\
WPO & 0.04 & 0.07 & 0.05 & 0.16 \\
WS & $-0.37^{*}$ & -0.29 & -0.13 & 0.20 \\
\hline
\end{tabular}

* $95 \%$ significance level. ${ }^{* *} 99 \%$ significance level.

SAM in September occurs in association with negative SIE anomalies over the WS, while in November a positive SAM tended to be associated with positive SIE over the IO. In December, a positive SAM index is associated with positive SIE over the RS. Our analysis indicates that the SAM's role in sea ice variability is rather complex and dependent on the region under consideration. 
Although at the Antarctic level no significant trends in the meridional moisture fluxes over the period 1979-2010 have been observed (Tsukernik and Lynch, 2013), the austral spring in 2016 stands out as very extreme in this respect, with 2016 ranking as the moistest (Fig. S3a) and warmest austral spring on record (Fig. S3b), over large areas covering Antarctica and the surrounding seas. The same holds for the Arctic region, with boreal autumn 2016 ranking as the moistest and warmest autumn on record over almost the whole Arctic basin (Fig. S3c and d). Generally speaking, both austral spring and boreal autumn 2016 have been characterized by enhanced poleward advection of moist and warm air. This exceptional event, occurring simultaneously in both polar regions, might be a direct or indirect consequence of the combined effect of the 2015/2016 El Niño event (Stuecker et al., 2017) and the fact that 2016, as a whole, was the warmest year on record (NOAA, 2017). Together, these two exceptional events could have triggered the release of large amounts of moisture in the atmosphere, and via particular large-scale atmospheric circulation patterns (e.g., Rossby waves, weaker jet stream) parts of this moisture have been carried out towards the poles.

In order to have a clear picture of the physical mechanisms that relate IWV and T2m to the variability in the Antarctic SIE, complementary modeling simulations are needed. By using observational and reanalysis data alone it is difficult to disentangle which of the potential drivers (e.g., IWV and $\mathrm{T} 2 \mathrm{~m}$ ) has a stronger impact on the sea ice variability. For the Arctic region, previous studies (Mortin et al., 2016; Kapsch et al., 2013; Park et al., 2015) suggested that the transport of heat and moisture into the Arctic during spring enhances the incoming surface longwave radiation, thereby controlling the initiation of the annual ice melt and setting the stage for the Arctic September ice minimum. Thus, our study can be used as an indicator that moisture transport should be considered in future studies as a potential driver of the Antarctic sea ice variability.

From the perspective of future climate projection, our results imply that a realistic simulation of the Antarctic SIE trend and variability also requires a proper simulation of both climate modes of variability (e.g., SAM) as well as extreme events (e.g., moisture intrusions, Rossby waves, atmospheric blocking). In conclusion, the 2016 austral spring event demonstrates that the present-day climate of the Antarctic continent and the surrounding areas allows for extensive sea ice reduction to occur. Whether such events are going to occur more frequently in the future is uncertain, but it is essential to understand and highlight the mechanisms responsible for triggering such events.

Data availability. All data sets used can be found in the references.

\section{The Supplement related to this article is available online at https://doi.org/10.5194/esd-9-939-2018-supplement.}

Author contributions. MI designed the study and wrote the paper. PS, KG, and RT helped write the paper and interpret the results.

Competing interests. The authors declare that they have no conflict of interest.

Acknowledgements. This study is promoted by Helmholtz funding through the Polar Regions and Coasts in the Changing Earth System (PACES) program of the AWI. Funding by the Helmholtz Climate Initiative REKLIM is gratefully acknowledged. Patrick Scholz was funded by the Collaborative Research Centre TRR 181 "Energy Transfer in Atmosphere and Ocean" funded by the German Research Foundation.

The article processing charges for this open-access publication were covered by a Research

Centre of the Helmholtz Association.

Edited by: Anders Levermann

Reviewed by: Joakim Kjellsson and one anonymous referee

\section{References}

Bracegirdle, T. J. and Marshall, G. J.: The reliability of Antarctic tropospheric pressure and temperature in the latest global reanalyses, J. Climate, 25, 7138-7146, 2012.

Cohen, J., Zhang, X., Francis, J., Jung, T., Kwok, R., Overland, J., Tayler, P. C., Lee, S., Laliberte, F., Feldstein, S., Maslowski, W., Henderson, G., Stroeve, J., Coumou, D., Handorf, D., Semmler, T., Ballinger, T., Hell, M., Kretschmer, M., Vavrus, S., Wang, M., Wang, S., Wu, Y., Vihma, T., Bhatt, U., Ionita, M., Linderholm, H., Rigor, I., Routson, C., Singh, D., Wendisch, M., Smith, D., Screen, J., Yoon, J., Peings, Y., Cheng, H., and Blackport, R.: Arctic change and possible influence on mid-latitude climate and weather: a US CLIVAR White Paper, edited by: Uhlenbrock, K., US CLIVAR, Washington, D.C., USA, p. 41, https://doi.org/10.5065/D6TH8KGW, 2018.

Collins, M. and Co-authors: Long-term climate change: Projections, commitments and irreversibility, in: Climate Change 2013: The Physical Science Basis, edited by: Stocker, T. F., Qin, D., Plattner, G.-K., Tignor, M., Allen, S. K., Boschung, J., Nauels, A., Xia, Y., Bex, V., and Midgley, P. M., Cambridge University Press, Cambridge, 1029-1136, 2014.

Comiso, J. C. and Nishio, F.: Trends in the sea ice cover using enhanced and compatible AMSR-E, SSM/I, and SMMR data, J. Geophys. Res., 113, C02S07, https://doi.org/10.1029/2007JC004257, 2008.

Dee, D. P., Uppala, S. M., Simmons, A. J., Berrisford, P., Poli, P., Kobayashi, S., Andrae, U., Balmaseda, M. A., Balsamo, G., Bauer, P., Bechtold, P., Beljaars, A. C., van de Berg, L., Bidlot, 
J., Bormann, N., Delsol, C., Dragani, R., Fuentes, M., Geer, A. J., Haimberger, L., Healy, S. B., Hersbach, H., Hólm, E. V., Isaksen, L., Kållberg, P., Köhler, M., Matricardi, M., McNally, A. P., Monge-Sanz, B. M., Morcrette, J., Park, B., Peubey, C., de Rosnay, P., Tavolato, C., Thépaut, J., and Vitart, F.: The ERA-interim reanalysis: Configuration and performance of the data assimilation system, Q. J. Roy. Meteor. Soc., 137, 553-597, 2011.

Drumond, A., Taboada, E., Nieto, R., Gimeno, L., Vicente-Serrano, S. M., and López-Moreno, J. I.: A Lagrangian analysis of the present-day sources of moisture for major ice-core sites, Earth Syst. Dynam., 7, 549-558, https://doi.org/10.5194/esd-7-5492016, 2016.

Fetterer, F., Knowles, K., Meier, W., and Savoie, M.: Sea Ice Index, Version 2, NSIDC - National Snow and Ice Data Center, Boulder, Colorado, USA, https://doi.org/10.7265/N5736NV7, 2016.

Gorodetskaya, I. V., Tsukernik, M., Claes, K., Ralph, M. F., Neff, W. D., and Van Lipzig, N. P. M.: The role of atmospheric rivers in anomalous snow accumulation in East Antarctica, Geophys. Res. Lett., 41, 6199-6206, https://doi.org/10.1002/2014GL060881, 2014.

Grosfeld, K., Treffeisen, R., Asseng, J., Bartsch, A., Bräuer, B., Fritzsch, B., Gerdes, R., Hendricks, S., Hiller, W., Heygster, G., Krumpen, T., Lemke, P., Melsheimer, C., Nicolaus, M., Ricker, R., and Weigelt, M: Online sea-ice knowledge and data platform, available at: http://www.meereisportal.de (last access: 6 August 2017), Alfred Wegener Institute for Polar and Marine Research \& German Society of Polar Research, Bremerhaven, 85, 143-155, https://doi.org/10.2312/polfor.2016.011, 2016.

Hall, A. and Visbeck, M.: Synchronous variability in the Southern Hemisphere atmosphere, sea ice, and ocean resulting from the Annular Mode, J. Climate, 15, 3043-3057, 2002.

Holland, M. M., Landrum, L., Kostov, Y., and Marshall, J: Sensitivity of Antarctic sea ice to the southern annular mode in coupled climate models, Clim. Dynam., 49, 1813, https://doi.org/10.1007/s00382-016-3424-9, 2017.

Ionita, M.: Mid range forecasting of the German Waterways streamflow based on hydrologic, atmospheric and oceanic data, Reports on polar and marine research, Alfred Wegener Institute for Polar and Marine Research, Bremerhaven, 711, 81 pp., 2017.

Ionita, M., Lohmann, G., and Rimbu, N.: Prediction of Elbe discharge based on stable teleconnections with winter global temperature and precipitation, J. Climate, 21, 6215-6226, https://doi.org/10.1175/2008JCLI2248.1, 2008.

Ionita, M., Dima, M., Lohmann, G., Scholz, P., and Rimbu, N.: Predicting the June 2013 European Flooding based on Precipitation, Soil Moisture and Sea Level Pressure, J. Hydrometeorol., 16, 598-614, https://doi.org/10.1175/JHM-D-14-0156.1, 2014.

Ionita, M., Tallaksen, L. M., Kingston, D. G., Stagge, J. H., Laaha, G., Van Lanen, H. A. J., Scholz, P., Chelcea, S., and Haslinger, K.: The European 2015 drought from a climatological perspective, Hydrol. Earth Syst. Sci., 21, 1397-1419, https://doi.org/10.5194/hess-21-1397-2017, 2017.

Jacobs, S. S. and Comiso, J. C.: Climate variability in the Amundsen and Bellingshausen Seas, J. Climate, 10, 697-709, 1997.

Kapsch, M.-L., Graversen, R. G., and Tjernstrom, M.: Springtime atmospheric energy transport and the control of Arctic summer sea-ice extent, Nat. Clim. Change, 3, 744-748, 2013.
Keller, L. M., Colwell, S., Lazzara, M. A., and Fogt, R. L. (Eds.): Antarctica - Surface Observations (in "State of the Climate in 2016"), B. Am. Meteorol. Soc., 98, S158-S160, 2017.

Kwok, R. and Comiso, J. C.: Spatial patterns of variability in Antarctic surface temperature: connections to the Southern Hemisphere Annular Mode and the southern oscillation, Geophy. Res. Lett., 29, 50-1-50-4, https://doi.org/10.1029/2002GL015415, 2002.

Lefebvre, W. and Goosse, H.: Influence of the Southern Annular Mode on the sea ice-ocean system: the role of the thermal and mechanical forcing, Ocean Sci., 1, 145-157, https://doi.org/10.5194/os-1-145-2005, 2005.

Lefebvre, W., Goosse, H., Timmermann, R., and Fichefet, T.: Influence of the Southern Annular Mode on the sea ice-ocean system, J. Geophys. Res., 109, C09005, https://doi.org/10.1029/2004JC002403, 2004.

Liu, J. P. and Curry, J. A.: Accelerated warming of the Southern Ocean and its impacts on the hydrological cycle and sea ice, P. Natl. Acad. Sci. USA, 107, 14987-14992, 2010.

Liu, J. P., Curry, J. A., and Martinson, D. G.: Interpretation of recent Antarctic sea ice variability, Geophys. Res. Lett., 31, L02205, https://doi.org/10.1029/2003GL018732, 2004.

Lorenz, C. and Kunstmann, H.: The Hydrological Cycle in Three State-of-the-Art Reanalyses: Intercomparison and Performance Analysis, J. Hydrometeorol., 13, 1397-1420, https://doi.org/10.1175/JHM-D-11-088.1, 2012.

Marshall, G. J.: Trends in the Southern Annular Mode from observations and reanalyses, J. Climate, 16, 4134-4143, 2003.

Meehl, G. A., Arblaster, J. M., Bitz, C. M., Chung, C. T. Y., and Teng, H.: Antarctic sea-ice expansion between 2000 and 2014 driven by tropical Pacific decadal climate variability, Nat. Geosci., 9, 590-595, https://doi.org/10.1038/NGEO2751, 2016.

Meier, W., Fetterer, F., Savoie, M., Mallory, S., Duerr, R., and Stroeve, J.: NOAA/NSIDC Climate Data Record of Passive Microwave Sea Ice Concentration, Version 2, 19792011, Natinal Snow and Ice Data Center, Boulder, Colorado, https://doi.org/10.7265/N55M63M1, 2013.

Meißner, D., Klein, B., and Ionita, M.: Development of a monthly to seasonal forecast framework tailored to inland waterway transport in central Europe, Hydrol. Earth Syst. Sci., 21, 6401-6423, https://doi.org/10.5194/hess-21-6401-2017, 2017.

Mortin, J., Svensson, G., Graversen, R. G., Kapsch, M.-L., Stroeve, J. C., and Boisvert, L. N.: Melt onset over Arctic sea ice controlled by atmospheric moisture transport, Geophys. Res. Lett. 43, 6636-6642, https://doi.org/10.1002/2016GL069330, 2016.

National Research Council: Seasonal to Decadal Predictions of Arctic Sea Ice: Challenges and Strategies, The National Academies Press, Washington, D.C., https://doi.org/10.17226/13515, 2012.

Nieto, R., da Rocha, R., Gimeno-Sotelo, L., Vázquez, M., Losada, L., and Gimeno, L.: Patterns of atmospheric moisture transport linked to Southern Ocean Sea ice coverage changes, in: Proceedings of First International Electronic Conference on the Hydrological Cycle, 12-16 November 2017, 4877, https://doi.org/10.3390/CHyCle-2017-04877, 2017.

NOAA: National Centers for Environmental information, Climate at a Glance: Global Time Series, published February 2017, http: //www.ncdc.noaa.gov/cag/, last access: 11 March 2017. 
Park, H.-S., Lee, S., Son, S.-W., Feldstein, S. B., and Kosaka, Y.: The impact of poleward moisture and sensible heat flux on Arctic winter sea ice variability, J. Climate, 28, 5030-5040, 2015a

Peixoto, J. P. and Oort, A. H.: Physics of Climate, Springer, New York, 520 pp., 1992.

Raphael, M. N.: The influence of atmospheric zonal wave three on Antarctic sea ice variability, J. Geophys. Res., 112, D12112, https://doi.org/10.1029/2006JD007852, 2007.

Raphael, M. N. and Hobbs, W.: The influence of the large-scale atmospheric circulation on Antarctic sea ice during ice advance and retreat seasons, Geophys. Res. Lett., 41, 5037-5045, 2014.

Schlosser, E., Haumann, F. A., and Raphael, M. N.: Atmospheric influences on the anomalous 2016 Antarctic sea ice decay, The Cryosphere, 12, 1103-1119, https://doi.org/10.5194/tc-12-11032018, 2018.

Serreze, M. C. and Stroeve, J.: Arctic sea ice trends, variability and implications for seasonal ice forecasting, 373, Philos. T. R. Soc. S.-A, https://doi.org/10.1098/rsta.2014.0159, 2015.

Serreze, M. C., Holland, M. M., and Stroeve, J.: Perspectives on the Arctic's shrinking sea-ice cover, Science, 315, 1533-1536, 2007.

Shu, Q., Song, Z., and Qiao, F.: Assessment of sea ice simulations in the CMIP5 models, The Cryosphere, 9, 399-409, https://doi.org/10.5194/tc-9-399-2015, 2015.

Simmons, A. J., Willett, K. M., Jones, P. D., Thorne, P. W., and Dee, D. P.: Low-frequency variations in surface atmospheric humidity, temperature and precipitation: Inferences from reanalyses and monthly gridded observational datasets, J. Geophys. Res., 115, D01110, https://doi.org/10.1029/2009JD012442, 2010.

Simpkins, G. R., Ciasto, L. M., Thompson, D. W., and England, M. H.: Seasonal Relationships between Large-Scale Climate Variability and Antarctic Sea Ice Concentration, J. Climate, 25, 5451-5469, https://doi.org/10.1175/JCLI-D-11-00367.1, 2012.

Stammerjohn, S. E. and Scambos, T. (Eds.): Antarctica (in "State of the Climate in 2016"), B. Am. Meteorol. Soc., 98, S155-S172, 2017.

Stammerjohn, S. E., Martinson, D. G., Smith, R. C., Yuan, X., and Rind, D.: Trends in Antarctic annual sea ice retreat and advance and their relation to El Niño-Southern Oscillation and Southern Annular Mode variability, J. Geophys. Res., 108, C03S90, https://doi.org/10.1029/2007JC004269, 2008.

Stammerjohn, S. E., Massom, R., Rind, D., and Martinson, D. G.: Regions of rapid sea ice change: An interhemispheric seasonal comparison, Geophys. Res. Lett., 39, L06501, https://doi.org/10.1029/2012GL050874, 2012.

Stroeve, J., Kattsov, V., Barrett, A., Serreze, M., Pavlova, T., Holland, M., and Meier, W.: Trends in Arctic sea ice extent from CMIP5, CMIP3 and observations, Geophys. Res. Lett., 39, L16502, https://doi.org/10.1029/2012GL052676, 2012.

Stroeve, J., Blanchard-Wrigglesworth, E., Guemas, V., Howell, S., Massonnet, F., and Tietsche, S.: Improving predictions of Arctic sea ice extent, Eos Trans. Am. Geophys. Union, 96, https://doi.org/10.1029/2015EO031431, 2015.
Stuecker, M. F., Bitz, C. M., and Armour, K. C.: Conditions leading to the unprecedented low Antarctic sea ice extent during the 2016 austral spring season, Geophys. Res. Lett., 44, 9008-9019, https://doi.org/10.1002/2017GL074691, 2017.

Tietäväinen, H. and Vihma, T.: Atmospheric moisture budget over Antarctica and the Southern Ocean based on the ERA-40 reanalysis, Int. J. Climatol., 28, 1977-1995, https://doi.org/10.1002/joc.1684, 2008.

Tsukernik, M. and Lynch, A. H.: Atmospheric Meridional Moisture Flux over the Southern Ocean: A Story of the Amundsen Sea, J. Climate, 26, 8055-8064, https://doi.org/10.1175/JCLI-D-12$00381.1,2013$.

Turner, J.: The El Niño-southern oscillation and Antarctica, Int. J. Climatol., 24, 1-31, https://doi.org/10.1002/joc.965, 2004.

Turner, J., Comiso, J. C. , Marshall, G. J., Lachlan-Cope, T. A., Bracegirdle, T., Maksym, T., Meredith, M. P., Wang, Z., and Orr, A.: Non-annular atmospheric circulation change induced by atmospheric ozone-depletion and its role in the recent increase of Antarctic sea ice extent, Geophys. Res. Lett., 36, L08502, https://doi.org/10.1029/2009GL037524, 2009.

Turner, J., Phillips, T., Marshall, G. J., Hosking, J. S., Pope, J. O., Bracegirdle, T. J., and Deb, P.: Unprecedented springtime retreat of Antarctic sea ice in 2016, Geophys. Res. Lett., 44, 6868-6875, https://doi.org/10.1002/2017GL073656, 2017.

Turner, T., Bracegirdle, J., Phillips, T., Marshalll, G. J., and Hoskins, J. S.: An initial assessment of Antarctic sea ice extent in the CMIP5 models, J. Climate, 26, 1473-1484, https://doi.org/10.1175/JCLI-D-12-00068.1, 2013.

Uppala, S., Dee, D., Kobayashi, S., Berrisford, P., and Simmons, A.: Towards a climate data assimilation system: status update of ERA-Interim, ECMWF Newslett No. 115, 1218 pp., http:// www.ecmwf.int/publications/newsletters/pdf/115rev.pd (last access: 17 August 2017), 2008.

Yang, W. and Magnusdottir, G.: Springtime extreme moisture transport into the Arctic and its impact on sea ice concentration, J. Geophys. Res.-Atmos., 122, 5316-5329, https://doi.org/10.1002/2016JD026324, 2017.

Yuan, N., Ding, M., Ludescher, J., and Bunde, A.: Increase of the Antarctic Sea Ice Extent is highly significant only in the Ross Sea, Sci. Rep., 7, 41096, https://doi.org/10.1038/srep41096, 2017.

Yuan, X. J.: ENSO-related impacts on Antarctic sea ice: A synthesis of phenomenon and mechanisms, Antarct. Sci., 16, 415-425, 2004,

Zhang, J. L.: Increasing Antarctic sea ice under warming atmospheric and oceanic conditions, J. Climate, 20, 2515-2529, 2007.

Zwally, H. J., Comiso, J. C., Parkinson, C. L., Cavalieri, D. J., and Gloersen, P.: Variability of Antarctic sea ice 1979-1998, J. Geophys. Res., 107, 3041, https://doi.org/10.1029/2000JC000733, 2002. 